\title{
Determination of Parameters Influencing Thermal Comfort in a Building
}

\author{
Emmanuel Ouédraogo ${ }^{1,2, *}$, Boureima Dianda ${ }^{1,3}$, Thierry Sikoudouin Maurice Ky ${ }^{1}$, \\ Abdoulaye Ouédraogo 1 \\ ${ }^{1}$ Department of Physics, Formation and Research Unit in Exact and Applied Sciences, University Ouaga 1 Pr Joseph KI-ZERBO, \\ Ouagadougou, Burkina Faso \\ ${ }^{2}$ Department of Physics and chemistry, Formation and Research Unit in Sciences and Technologies, University of Ouahigouya, Ouahigouya, \\ Burkina Faso \\ ${ }^{3}$ Department of Energy, Institute of Research in Applied Sciences and Technologies, Ouagadougou, Burkina Faso
}

\section{Email address:}

ouedem7@gmail.com (E. Ouédraogo),diand8fr@gmail.com (B. Dianda), thierrysmky@gmail.com (T. S. M. Ky), askia366@yahoo.fr (A. Ouédraogo)

\section{To cite this article:}

Emmanuel Ouédraogo, Boureima Dianda, Thierry Sikoudouin Maurice Ky, Abdoulaye Ouédraogo. Determination of Parameters Influencing Thermal Comfort in a Building. Science Journal of Energy Engineering. Vol. 6, No. 3, 2018, pp. 42-48. doi: 10.11648/j.sjee.20180603.11

Received: September 20, 2018; Accepted: October 6, 2018; Published: October 27, 2018

\begin{abstract}
This paper presents a theoretical and an experimental study on the determination of thermal phase shift time and damping factors of building walls. The work consisted in evaluating the thermal comfort in a building. This study is a contribution to put in place a thermal regulation in Burkina Faso, a country with a dry tropical climate. This regulation will, in its application, reduce the energy consumption related to air conditioning in buildings. To do this, we theoretically determine the parameters influencing this comfort using the admittance method. This method makes it possible to analyze the thermal response of a building to a periodic energy demand. It is based on the modeling of the building component by the quadrupole method resulting from the writing of the thermal problem in the form of transfer matrix products. The principle is to link the flows and temperatures of both sides of a homogeneous wall through the equation of heat and the Fourier transform. The calculation method is validated by experimental results. For simple sheet walls based on their compositions, damping factors range from about $37.9 \%$ to $79.7 \%$ and thermal phase shift time from about 3.9 hours to 7.4 hours. However, the values of these parameters are better when the walls are double-sheeted, the maximum value of the damping factor is $11.5 \%$ and the minimum value of the thermal phase shift time is $9.7 \mathrm{~h}$. The values of Mean Bias Difference (MBD) and Root Mean Square Difference (RMSD) show that the theoretical and experimental results are quite concordant. The admittance method can be used to evaluate the performance of building walls.
\end{abstract}

Keywords: Time Lag, Decrement Factor, Thermal Comfort, Thermal Amplitudes, Admittance Method

\section{Introduction}

Thermal comfort is an important parameter in habitats because of its impact on the quality of indoor environments, the health and productivity of the occupant. This parameter is regulated by standards that ensure the conformity of indoor environments to the requirements of this thermal comfort. To meet the requirements, this internal atmosphere is ensured in tropical countries during the hot season by active air conditioning. The purchase of air conditioners for air cooling in homes has the effect of warming the air outside and for a city like Athens, there is a temperature gradient of up to $14^{\circ} \mathrm{C}$ in summer between the city and its periphery [1]. This entropic release leads to a constant oversizing of air cooling and air conditioning systems. These considerations are at the root of high energy consumption and problems of occupant discomfort. The improvement of comfort conditions and the reduction of air-conditioning costs by low-cost ecological means of energy are considered today as a top priority by both users and energy distributors. Enescu [2] reviewed the most used models and thermal comfort indicators with their variants. The characteristics of these models and their use can 
predict the indoor air temperature and the average vote prediction index for energy management. The works of Kim et al [3] give a new approach to thermal comfort modeling that predicts the response to an individual's thermal comfort, instead of the average response of a large population. The data collected in the everyday environment of individuals makes it possible to understand the comfort requirements of these individuals. Rahmillah et al [4] studied thermal comfort in non-air-conditioned kitchens in tropical countries. They showed that $71 \%$ of respondents consider that morning cooking is comfortable. Wong et al [5] put into evidence the role of objective and subjective factors on human thermal comfort. They showed the relationship between urban green infrastructure, microclimate and thermal comfort in order to help urban planning to better use green spaces for microclimate regulation. Alamin et al [6] have shown that the thermal comfort conditions of users in indoor environments have a direct effect on the productivity of these users. They have put in place a predictive control (MPC) based on an economic model to achieve the thermal comfort of users. As the heat transmission in the building is through the envelope, it is necessary to determine the parameters of the walls influencing the thermal comfort. These parameters are the thermal phase shift time and the damping factors. The study made by Coulibaly et al. [7] on the optimization of the envelope of a bioclimatic building, highlights the effect of the thermal inertia of the different layers of materials of the double sheets of the walls on the energy consumption in air conditioning and comfort. For this study, we determine two (02) parameters influencing the comfort (the damping factor and the thermal phase shift time) as a function of the composition of the walls. The different walls consist of either single sheet or double sheets with or without air gap. The thermal resistances of the air barriers used for wall insulation are determined from correlations [8]. Several works concerning the analytical resolution of the one-dimensional variable-regime heat equation exist in the literature. Maillet et al [9] and Sambou used the quadrupole method which is based on the use of the Laplace transformation to solve analytically the one-dimensional heat equation in variable regime. The quadrupole or admittance method will allow us to calculate damping factors and thermal phase shift time for different wall configurations. The admittance method makes it possible to characterize the thermal inertia of a building by considering a thermal response to harmonic solicitations. Admittance measures the ability of a building element to store and retrieve energy over a daily cycle and can be defined as the ratio of the flow variation to the temperature change over a 24-hour period. This method was developed by Loudon then by Pertherbridge before being adopted by CIBS in 1975 which today became the CIBSE (the Chartered Institution of Building Services Engineers). Milbank analyzed the thermal response of a building to a periodic energy demand using the admittance approach. He classified the solutions to the equations, which represent the evolution of the temperature due to the phenomenon of conduction through the elements of the buildings in two types: in the first case, the temporal variation of the temperature and the energy flows are in periodic regime and are repeated during the days while in the second case, they vary unpredictably from one day to another. The solutions in the first case have the simplest form and are the basis of the admittance method.

\section{Methodology}

\subsection{Building Parameters Influencing Thermal Comfort}

The main parameters of the envelope influencing the thermal and energy performance of the building are: the overall transmission coefficient, the damping factor and the thermal phase shift time. In this article, we are interested in the last two (2) parameters (the damping factor and the thermal phase shift time).

\subsubsection{Damping Factor and Thermal Phase Shift Time}

The building envelope is subject to daily or seasonal temperature variations according to a periodic regime. The thermal phase shift time and the damping factor allow to characterize the thermal inertia according to the period. Several calculation methods make possible to determine the phase shift values (delay) and the quantity of flux that passes through the wall (gains or damping). Inputs (gains) will depend on the thermal wave profiles to which they are subjected.

The thermal phase shift time is the time required for the indoor temperature to reach its maximum from the moment when the outside temperature peak occurs. It evolves with the inertia of the building and is determined by equation 1 :

$$
\varphi=t_{T_{i n, \max }}-t_{T_{e x, \max }}
$$

Where: $\phi(h)$ is the thermal phase shift time, $t_{\text {Tin, max }}$, and $t_{\text {Tex,max }}$ are the times at which the peaks of internal and external temperatures are reached.

The damping factor is the ratio of the amplitudes of the indoor and the outdoor temperatures. The lower the damping factor, the lower the internal temperatures are. It is determined by Equation 2:

$$
f=\frac{\Delta T_{i n}}{\Delta T_{e x}}
$$

With $\Delta T_{i n}$ : amplitude of the internal temperature and $\Delta T_{e x}$ : amplitude of the external temperature. These properties of the building envelope are important because they allow to characterize the internal environment. They are evaluated according to the indoor and outdoor temperatures and provide information on the behavior of the envelopes.

They can also be calculated from the thermo-physical properties of the materials constituting the envelope. The thermal phase shift time and damping factor of a multilayer wall can be evaluated using the expressions of the admittances.

For the damping factor, its expression is given by equation 3 [11]: 


$$
f=\frac{|Y|}{U_{p}}
$$

With: $f$ the damping factor and $U_{p}\left(W \cdot m^{-2} \cdot K^{-1}\right)$ the overall exchange coefficient of the wall.

As for the thermal phase shift time, it is evaluated by equation 4 [11]:

$$
\varphi=\frac{P}{2 \pi} \arg [Y]
$$

With: $\phi(h)$ the thermal phase shift time and $P=24 \mathrm{~h} ; Y$ $\left(W \cdot m^{-2} \cdot K^{-1}\right)$ the transmittance determined by the admittance method.

\subsubsection{Admittance Method}

Admittances are complex numbers that characterize the dynamic thermal behavior of a building component. ISO 13786 provides methods for calculating these characteristics. It also specifies the required information on building materials as these characteristics are dependent on how the materials are combined to form building components. These methods are based on the modeling of the building component by the quadrupole method resulting from the writing of the thermal problem in the form of transfer matrix products which originally is used in the field of electricity. The principle consists, by means of the equation of heat and the Fourier transform, to link the flows and the temperatures of both sides of a homogeneous wall by the equation 5 [14]:

$$
\left(\begin{array}{l}
\theta_{e} \\
\varphi_{e}
\end{array}\right)=\left(\begin{array}{ll}
A & B \\
C & D
\end{array}\right)\left(\begin{array}{l}
\theta_{i} \\
\varphi_{i}
\end{array}\right)
$$

With:

$$
\begin{gathered}
A=D=\cosh \left(e \sqrt{\frac{j \omega}{\alpha}}\right) \\
B=\frac{1}{b \sqrt{j \omega}} \sinh \left(e \sqrt{\frac{j \omega}{\alpha}}\right) \\
C=b \sqrt{j \omega} \sinh \left(e \sqrt{\frac{j \omega}{\alpha}}\right)
\end{gathered}
$$

The pairs $\left(\theta_{e}, \phi_{e}\right)$ and $\left(\theta_{i}, \phi_{i}\right)$ are the state variables respectively of the outer and inner surfaces. $\alpha\left(m^{2} \cdot s^{-1}\right)$ is the thermal diffusivity; $b\left(W \cdot s^{1 / 2} \cdot m^{-2} \cdot K^{-1}\right)$ is the thermal effusivity; $e(m)$ is the thickness and $\left(j^{2}=-1\right)$.

For a multilayer wall, the resulting transfer matrix of the product of the elementary matrices of the set of layers is written (equation 9):

$$
M=\left(\begin{array}{ll}
H_{11} & H_{12} \\
H_{21} & H_{22}
\end{array}\right)=\left(\begin{array}{ll}
A_{1} & B_{1} \\
C_{1} & D_{1}
\end{array}\right)\left(\begin{array}{cc}
A_{2} & B_{2} \\
C_{2} & D_{2}
\end{array}\right) \cdots\left(\begin{array}{ll}
A_{n} & B_{n} \\
C_{n} & D_{n}
\end{array}\right)
$$

For a purely resistive layer (the superficial layers for example), we will have an elementary matrix equal to (equation 10):

$$
M=\left(\begin{array}{cc}
1 & R \\
0 & 1
\end{array}\right)
$$

With $R=R_{s, i n}$ or $R_{s, e x}$ or $R=e_{\text {iso }} / \lambda_{\text {iso }}$ for an insulator [14]. For an air space, the thermal capacity is neglected. Therefore, if $R_{a}$ is the thermal resistance of the air space, including convection and radiation, its transfer matrix is given by equation 11:

$$
M=\left(\begin{array}{cc}
1 & R_{a} \\
0 & 1
\end{array}\right)
$$

When the wall is symmetrical, elements $H_{12}$ and $H_{21}$ are identical.

The periodic dynamic admittances of the wall are expressed by equations 12,13 and 14 :

$$
\begin{gathered}
X=\frac{H_{22}}{H_{12}} \\
Y=\frac{1}{H_{12}} \\
Z=\frac{H_{21}}{H_{12}}
\end{gathered}
$$

$X\left(W \cdot m^{-2} \cdot K^{-1}\right)$ and $Z\left(W \cdot m^{-2} \cdot K^{-1}\right)$ represent the admittances of the outer and inner sides and $Y\left(W \cdot m^{-2} \cdot K^{-1}\right)$ the transmittance.

The interior surfaces of walls exposed to air and made of heavy materials such as concrete, brick or stone have an important ability to store periodic energy flows. Their admittances are then high and as a result, fluctuations in the temperature in the rooms are reduced.

\subsection{Determination of the Expressions of Transmittances of Different Walls}

We have determined expressions of $A, B, C$ and $D$ without the unit vector $(j)$ on the imaginary axis of the complex plane under the radicals.

We have:

$$
\begin{gathered}
A=D=\cosh \left(e \sqrt{\frac{j \omega}{\alpha}}\right) \\
A=\cosh \left(e \sqrt{\frac{2 \pi \cdot j}{P \cdot \alpha}}\right)=\cosh \left(\sqrt{\frac{\pi}{P \cdot \alpha}(1+j)^{2}} \cdot e\right)
\end{gathered}
$$

With

$$
2 \cdot j=(1+j)^{2}
$$

Let us set: 


$$
k=\sqrt{\frac{\pi}{p \cdot \alpha}} \cdot e
$$

For the establishment of the expressions of B and C, let us

$$
\begin{gathered}
A=\cosh (k) \cdot \cos (k)+j \cdot \sinh (k) \cdot \sin (k) \\
B=\frac{\delta}{2 \lambda}[\sinh (k) \cdot \cos (k)+\cosh (k) \cdot \sin (k)+j(\cosh (k) \cdot \sin (k)-\sinh (k) \cdot \cos (k))] \\
C=\frac{\lambda}{\delta}[\sinh (k) \cdot \cos (k)-\cosh (k) \cdot \sin (k)+j(\sinh (k) \cdot \cos (k)+\cosh (k) \cdot \sin (k))]
\end{gathered}
$$

The expression of the transfer matrix of a single wall is:

$$
M=\left(\begin{array}{ll}
H_{11} & H_{12} \\
H_{21} & H_{22}
\end{array}\right)=\left(\begin{array}{cc}
1 & R_{S, e x} \\
0 & 1
\end{array}\right)\left(\begin{array}{cc}
A & B \\
C & A
\end{array}\right)\left(\begin{array}{cc}
1 & R_{S, i n} \\
0 & 1
\end{array}\right)
$$

The $H_{12}$ component of the matrix is given by the following formulas:

$$
H_{12}=\left(R_{S, e x}+R_{S, i n}\right) \cdot A+R_{S, e x} \cdot R_{S, i n} \cdot C+B
$$

For the double sheet wall, neglecting the contact resistance, its transfer matrix is given by the following relation 24 :

$$
M=\left(\begin{array}{ll}
H_{11} & H_{12} \\
H_{21} & H_{22}
\end{array}\right)=\left(\begin{array}{cc}
1 & R_{S, e x} \\
0 & 1
\end{array}\right) \cdot\left(\begin{array}{cc}
A_{1} & B_{1} \\
C_{1} & A_{1}
\end{array}\right) \cdot\left(\begin{array}{cc}
A_{2} & B_{2} \\
C_{2} & A_{2}
\end{array}\right) \cdot\left(\begin{array}{cc}
1 & R_{S, i n} \\
0 & 1
\end{array}\right)
$$

The expression of component $H_{12}$ is given by equation 25 :

$$
H_{12}=\left(B_{2}+R_{S, \text { in }} \cdot A_{2}\right)\left(A_{1}+R_{S, e x} \cdot C_{1}\right)+\left(A_{2}+R_{S, \text { in }} \cdot C_{2}\right)\left(B_{1}+R_{S, e x} \cdot A_{1}\right)
$$

For a double sheet wall with an air gap or an insulator between the walls, the matrix is given by equation 26 :

$$
M=\left(\begin{array}{ll}
H_{11} & H_{12} \\
H_{21} & H_{22}
\end{array}\right)=\left(\begin{array}{cc}
1 & R_{S, e x} \\
0 & 1
\end{array}\right) \cdot\left(\begin{array}{cc}
A_{1} & B_{1} \\
C_{1} & A_{1}
\end{array}\right) \cdot\left(\begin{array}{cc}
1 & R_{a} \\
0 & 1
\end{array}\right) \cdot\left(\begin{array}{cc}
A_{2} & B_{2} \\
C_{2} & A_{2}
\end{array}\right) \cdot\left(\begin{array}{cc}
1 & R_{S, \text { in }} \\
0 & 1
\end{array}\right)
$$

The expression of component $H_{12}$ is given by equation 27:

$$
H_{12}=\left(B_{2}+R_{S, i n} \cdot A_{2}\right)\left(A_{1}+R_{S, e x} \cdot C_{1}\right)+\left(A_{2}+R_{S, i n} \cdot C_{2}\right)\left[R_{a}\left(A_{1}+R_{S, e x} \cdot C_{1}\right)+B_{1}+R_{S, e x} \cdot A_{1}\right]
$$

If the insulation is different from air, $\mathrm{R}_{\mathrm{a}}$ is replaced by $\mathrm{R}\left(R=e_{\text {iso }} / \lambda_{\text {iso }}\right)$. The different expressions of $Y$ are obtained by taking the inverse of those of $H_{12}$.

Simulations are done using the materials presented in Table 1.

Table 1. Thermal Conductivity of Material and Wall [8].

\begin{tabular}{llll}
\hline Materials & Thermal conductivity $\left(\boldsymbol{W} \cdot \boldsymbol{m}^{-1} \cdot \boldsymbol{K}^{\mathbf{L}}\right)$ & Thermal diffusivity $\left(\mathbf{1 0}^{-7} \boldsymbol{m}^{\mathbf{2}} \cdot \boldsymbol{s}^{-\mathbf{l}}\right)$ & Thermal conductivity of the wall $\left(\boldsymbol{W} \cdot \boldsymbol{m}^{-1} \cdot \boldsymbol{K}^{-1}\right)$ \\
\hline Cement hollow block [15] & 1,2 & & 1,193 \\
BTC in Earth & $0.556 \pm 0.006$ & $1.767 \pm 0.016$ & $0.644 \pm 0.005$ \\
BTC in Paper-Earth & $0,490 \pm 0,004$ & $2,360 \pm 0,034$ & $0,588 \pm 0,006$ \\
BTC in Earth-Cement & $0,671 \pm 0,009$ & $2,180 \pm 0,023$ & $0,742 \pm 0,011$ \\
BTC in Earth-Cement-Paper & $0,588 \pm 0,006$ & $2,140 \pm 0,023$ & $0,671 \pm 0,008$ \\
\hline
\end{tabular}

Table 1 gives the global coefficients of convection (he, hi) on the walls and the absorption coefficients of the walls of the building.

The thicknesses of the different walls (envelope and sheets) are $14 \mathrm{~cm}$, those of the double sheet of the envelope are $28 \mathrm{~cm}$ and those of the double sheet walls of the envelope with insulation are $28 \mathrm{~cm}$ plus the thickness of the insulation. The values of the surface transmission coefficients of the walls are given in figure 1. 


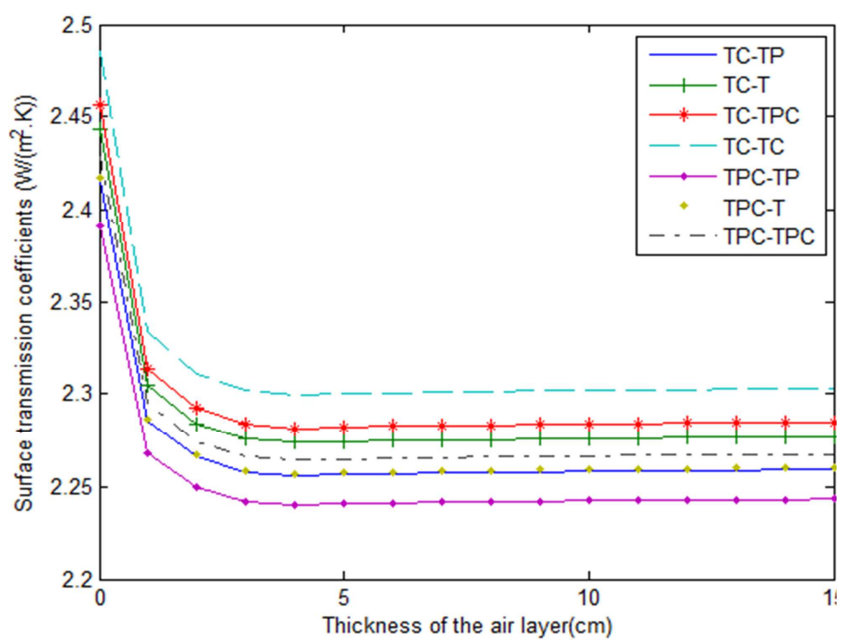

Figure 1. Surface transmission coefficients of the double-sheeted walls according to the thickness of the air layer [8].

With TC-T: Earth Cement Paper, TPC-T: Earth Paper Cement Earth, TC-TP: Earth CementEarth Paper, TC-TPC: Earth Cement Earth Paper Cement, TC-TC: Earth CementEarth Cement, TPC-TP: Earth Paper Cement Earth Paper, TPC-TPC: Earth Paper Cement Earth Paper Cement.

\subsection{Experimental Study}

Measurements have been made on compressed-earth block walls, stabilized compressed earth block and cinder block and for different types of walls (single sheet and double sheet). The experimental setup is shown in Figure 2:

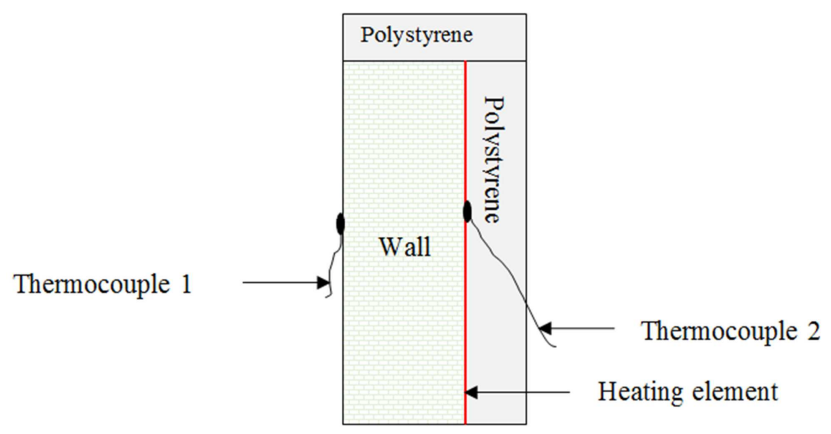

Figure 2. Experimental device for measuring surface temperatures.

Figure 3 shows a front view of the device

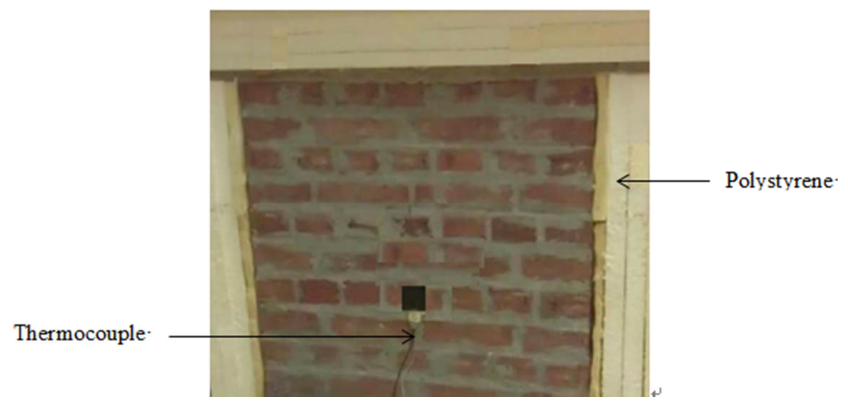

Figure 3. Experimental setup of the wall and insulation.

Thermocouple 1 determines the outside temperature and thermocouple 2 measures the temperature of the inner wall surface. The device is placed in the shadow.

To evaluate the level of correlations, the statistical parameters such as Mean Bias Difference (MBD) and Root Mean Square Difference (RMSD) root mean for the day are calculated by equations (28) and (29):

$$
\begin{gathered}
M B D_{j}=\frac{\sum_{j=1}^{n}\left(x-y_{j}\right)}{n} \cdot \frac{1}{y} \cdot 100 \\
R M S D_{j}=\sqrt{\frac{\sum_{j=1}^{n}\left(x-y_{j}\right)^{2}}{n}} \cdot \frac{1}{y} \cdot 100
\end{gathered}
$$

Where: $x$ is the theoretical value, $y_{j}$ the experimental value of the day $j$ and $\bar{y}$ the average of $y_{j}$. They show the level of correlation between experimental and theoretical results.

\section{Results and discussions}

\subsection{Theoretical Results}

Table 2 gives the values of the daily thermal phase shift time and the damping factors of single sheet and double sheet walls.

Table 2. Values of thermal phase shift time and damping factors.

\begin{tabular}{lll}
\hline Composition of the wall & $\begin{array}{l}\text { Damping factors } \\
(\%)\end{array}$ & $\begin{array}{l}\text { Thermal phase } \\
\text { shift time }(\boldsymbol{h})\end{array}$ \\
\hline Earth (T) & $43,681 \pm 1,095$ & $6,697 \pm 0,142$ \\
Earth Paper (TP) & $37,949 \pm 0,948$ & $7,355 \pm 0,155$ \\
Earth Cement Paper (TPC) & $43,677 \pm 1,095$ & $6,706 \pm 0,143$ \\
Earth Cement (TC) & $44,839 \pm 1,123$ & $6,582 \pm 0,141$ \\
Cement hollow block & $79,693 \pm 1,995$ & $3,907 \pm 0,085$ \\
Earth Cement Paper (TC-T) & $11,119 \pm 0,275$ & $10,561 \pm 0,225$ \\
Earth Cement Earth Paper (TC-TP) & $9,551 \pm 0,241$ & $9,883 \pm 0,215$ \\
Earth Cement Earth Paper Cement & $11,144 \pm 0,278$ & $10,589 \pm 0,225$ \\
(TC-TPC) & $11,525 \pm 0,287$ & $10,786 \pm 0,231$ \\
Earth Cement Earth Cement (TC-TC) & $10,584 \pm 0,265$ & $10,363 \pm 0,223$ \\
Earth Paper Cement Earth (TPC-T) & $9,087 \pm 0,229$ & $9,686 \pm 0,208$ \\
$\begin{array}{l}\text { Earth Paper Cement Earth Paper } \\
\text { (TPC-TP) }\end{array}$ & & \\
Earth Paper Cement Earth Paper & $10,602 \pm 0,268$ & $10,391 \pm 0,221$ \\
Cement (TPC-TPC) & & \\
Earth Paper Cement Earth Cement & $10,953 \pm 0,275$ & $10,588 \pm 0,224$ \\
(TPC-TC) & &
\end{tabular}

The values of thermal phase shift time for double-sheeted walls are lower than those obtained by Coulibaly et al in their work on the thermal study of a double-walled bioclimatic building [7]. There is a significant thermal phase shift time (minimum 6 hours) between the internal and external peaks of the temperatures for the different compositions of the walls except that in block which has a small thermal phase shift time (about 4 hours). Apart from the cinderblock walls with a high damping factor $(79.693 \%)$, the other walls have damping factors lesser than $45 \%$. Then the temperatures crossing these walls (internal temperatures) are damped. In 
addition, the internal temperatures of the double sheet walls are the most damped (the lowest damping factors). So the earth materials (compressed earth block) have good thermal performance than the cement block.

Figures 4, 5 and 6 respectively show damping factors, thermal phase shift time and thermal amplitudes $(\Delta T i)$ of the internal temperatures of the walls with double sheets as a function of the thickness of the air gap. These different results are obtained from the quadrupole method or admittances.

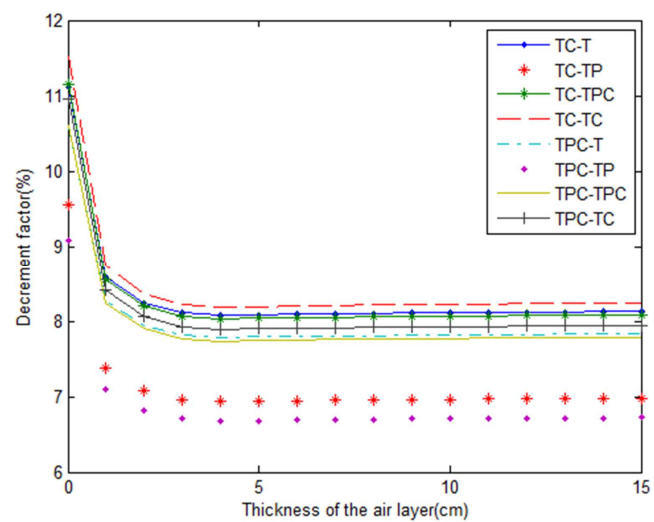

Figure 4. Values of the decrement factors of the walls with double sheet according to the thickness of the air space.

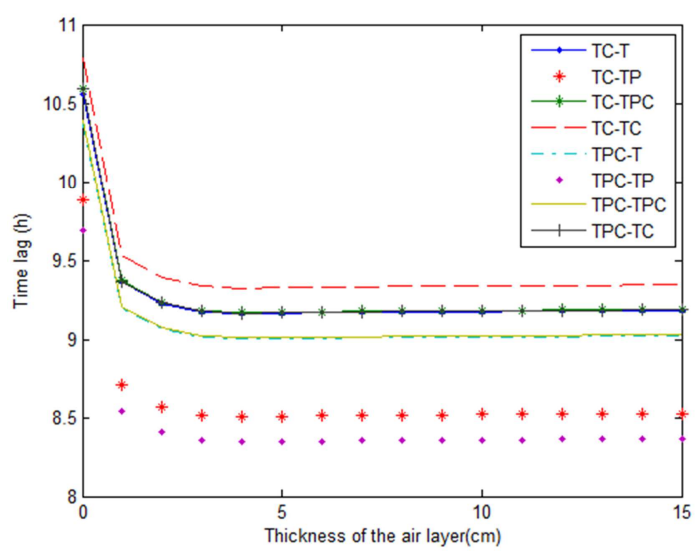

Figure 5. Values of the time lag of double-sheeted walls according to the thickness of the air space.

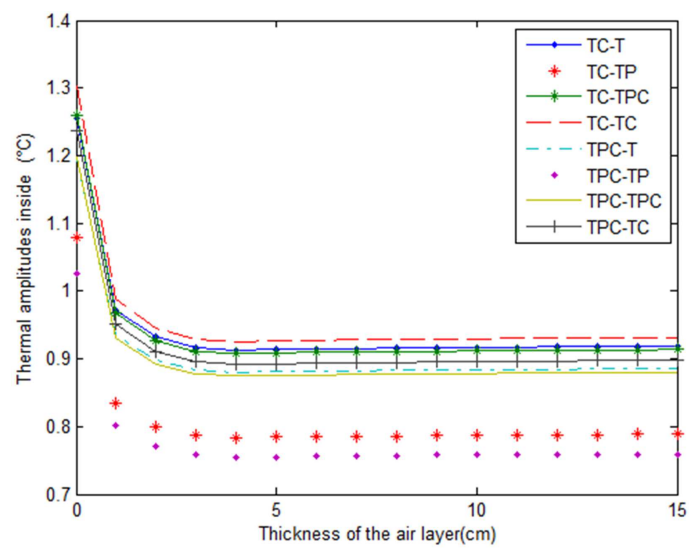

Figure 6. Values of thermal amplitudes inside a habitat which walls are double-sheeted according to the thickness of the air space.
We notice a decrease in the different values for thicknesses of the air gap lesser than $4 \mathrm{~cm}$ and a very small increase beyond $4 \mathrm{~cm}$. This is explained by the properties (thermal resistances) of the air gap used [8].

The temperatures crossing the different walls are more and more damped when the thickness of the air varies from $0 \mathrm{~cm}$ to $4 \mathrm{~cm}$ (figure 4), they are even more damped for the walls containing the compressed earth blocks in Paper-Earth (TP). With a thickness of the air gap of $1 \mathrm{~cm}$, the amplitude of the temperature passing through the different types of double sheet walls is reduced by at least $23 \%$. As for the values of the thermal phase shift time (figure 5), they are greater than 8 hours regardless of the type of walls. The drop in thermal phase shift time values for thicknesses of air lesser than $4 \mathrm{~cm}$ is due to the presence of air with low thermal inertia. The daily thermal amplitude (figure 6) represents the difference between the maximum and the minimum of the temperatures having crossed the walls during a day. The maximum external heat amplitude (typical year data) is $11.3^{\circ} \mathrm{C}$. A drop of at least $23 \%$ in the values of the daily thermal amplitudes is also observed when the thickness of the air gap goes from 0 to $1 \mathrm{~cm}$ for the different types of walls. So better conditions of comfort are obtained for walls with high inertia associated with a layer of insulating materials such as air.

\subsection{Experimental Results}

Figure 7 and Table 3 show the hourly temperature profiles and values of the damping factors and the thermal phase shift time respectively.

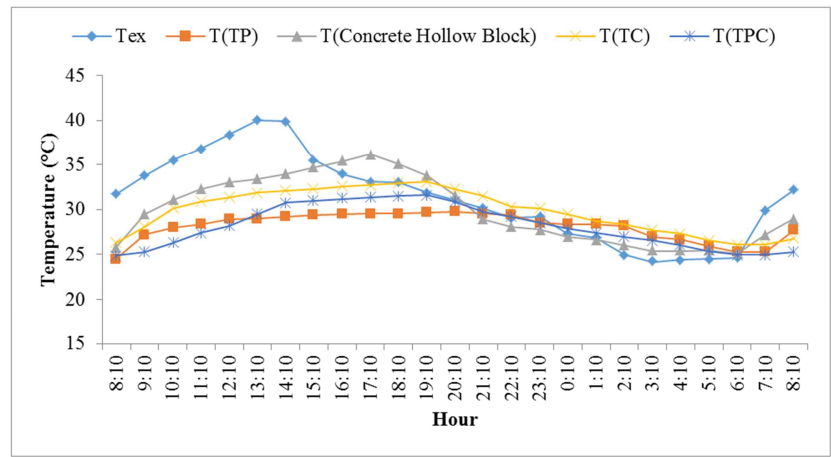

Figure 7. Profile of measured hourly temperatures.

The temperature amplitudes of the unexposed surface are damped. The smallest amplitude is obtained for the TP wall, which confirms the insulating nature of this material.

Table 3. Damping factors and thermal phase shift times.

\begin{tabular}{lll}
\hline Wall & Decrement factor (\%) & Time lag (h) \\
\hline Earth Paper (TP) & 33,544 & 7 \\
Earth Paper Cement (TPC) & 42,405 & 6 \\
Earth Cement (TC) & 44,304 & 6 \\
Cement hollow block & 70,253 & 4 \\
\hline
\end{tabular}

The values of the damping factors and the thermal phase shift time are of the same order as those simulated.

Measurements of temperature values over a ten (10) day 
period allowed to obtain MBD and RMSD values (Table 4)

Table 4. MBD and RMSD Values.

\begin{tabular}{lllll}
\hline \multirow{2}{*}{ Wall } & \multicolumn{2}{l}{ Decrement factors (\%) } & \multicolumn{2}{l}{ Time lag (h) } \\
\cline { 2 - 5 } & MBD (\%) & RMSD (\%) & MBD (\%) & RMSD (\%) \\
\hline Earth Paper (TP) & 2,275 & 7,390 & 2,153 & 8,607 \\
Earth Paper Cement & 2,468 & 9,653 & $-5,549$ & 9,398 \\
(TPC) & & 5,455 & 4,476 & 8,541 \\
Earth Cement (TC) & $-1,480$ & 4,401 & $-5,628$ & 7,815 \\
Cement hollow & 1,231 & & & \\
block
\end{tabular}

The values of RMSD and MBD are lesser than $10 \%$. This is due to the small differences between the theoretical and experimental data of the two (02) parameters over these ten (10) days. The values of these parameters are of the same order as those obtained by Janjai $[16,17]$ and by Coulibaly et al [18]. We can therefore say that the theoretical and experimental values of the damping factors and the thermal phase shift time are concordant. Therefore the model used for simulation is well-suited.

\section{Conclusion}

This study made possible to determine, theoretically and experimentally, the values of the thermal phase shift time, the damping factors according to the type of walls. With the use of double-sheeted walls incorporating insulation, we have seen a considerable reduction in damping factors and an increase in the number of hours of the thermal phase shift time. The values of the measured temperatures showed that the thermal comfort cannot be reached in the premises and this in spite of the good results of the characteristics of walls. For comfort in the building, double sheet walls with insulation are recommended, because these types of walls have the best thermal performance (large thermal phase shift time and low damping factors). They also have the weakest internal thermal amplitudes. The MBD and RMSD values show that the theoretical and experimental results are fairly consistent. The admittance method can therefore be used to evaluate the thermal performance of the walls of a building.

\section{References}

[1] N. Fezzioui, M. Benyamine, N. Tadj, B. Draoui et S. Larbi, (2012). Performance énergétique d'une maison à patio dans le contexte maghrébin (Algérie, Maroc, Tunisie et Libye), Revue des Energies Renouvelables 15 (3) 399-405.

[2] Diana Enescu, (2017). A review of thermal comfort models and indicators for indoor environments. Renewable and Sustainable Energy Reviews, 79, 1353-1379.

[3] Joyce Kim Stefano Schiavon, Gail Brager, (2018). Personal comfort models - A new paradigm in thermal comfort for occupant-centric environmental control. Building and Environment, 132, 114-124.

[4] Fety Ilma Rahmillah, Agustina Hotma Uli Tumanggor and Amarria Dila Sari, (2017). The Analysis of Thermal Comfort in Kitchen. IOP Conf. Series: Materials Science and
Engineering, 215, 012033

[5] Yafei Wang, Rudolf de Groot, Frank Bakker, Heinrich Wörtche, and Rik Leemans, (2017). Thermal comfort in urban green spaces: a survey on a Dutch university campus. International Journal of Biometeorology, 61(1) 87-101.

[6] Yaser Imad Alamin, María del Mar Castilla, José Domingo Álvarez, and Antonio Ruano, (2017). An Economic ModelBased Predictive Control to Manage the Users' Thermal Comfort in a Building. Energies 321 (10) 1-18.

[7] Ousmane Coulibaly, Abdoulaye Ouedraogo, Jean Koulidiati et Pierre Abadie, (2013). Etude thermique d'un bâtiment bioclimatique en double paroi dénommée «Newango», Revue Liaison Énergie-Francophonie, $\mathrm{n}^{\circ} 942^{\mathrm{e}}$ et $3^{\mathrm{e}}$ trimestre.

[8] Emmanuel Ouedraogo, (2015). Détermination des données climatiques de base et caractérisation des blocs de terre comprimée pour l'étude du confort thermique dans le bâtiment en climat tropical sec, Thèse de doctorat, Université de Ouagadougou.

[9] Maillet D., Andre S., Batsale J-C., Degiovanni A., Moyne C., (2000). Thermal Quadrupoles. Solving the heat equation through integral transforms. United Kingdom: John Wiley \& Sons, $370 \mathrm{p}$.

[10] Vincent Sambou, (2008) Transferts thermiques instationnaires : vers une optimisation de parois de bâtiments, Thèse de doctorat, Université de Toulouse.

[11] Layal Chahwane, (2011). Valorisation de l'inertie thermique pour la performance énergétique des bâtiments. Thèse de doctorat, Université de Grenoble.

[12] ISO 7730:1994, Ambiances thermiques modérées Détermination des indices PMV et PPD et spécifications des conditions de confort thermique. AFNOR. Paris.

[13] La norme ISO 13786, (2017). Performance thermique des composants de bâtimentCaractéristiques thermiques dynamiquesMéthodes de calcul. AFNOR. Paris.

[14] D. Defer, J. Shen, S. Lassue, and B. Duthoit, (2002). Nondestructive testing of a building wall by studying natural thermal signals. Energy and Buildings, 34(1) 63-69.

[15] Ousmane Coulibaly, (2011). Contribution à l'élaboration d'une réglementation thermique et énergétique des bâtiments au Burkina Faso : Données de base multiparamétriques et modélisation thermo-aéraulique sous CoDyBa et TRNSYS. Thèse de doctorat, Université de Ouagadougou.

[16] S. Janjai, A. Sripradit, R. Wattan, S. Buntoung, S. Pattarapanichai, and I. Masiri, (2013). A Simple SemiEmpirical Model for the Estimation of Photosynthetically Active Radiation from Satellite Data in the Tropics. International Journal of Photoenergy, $6 \mathrm{p}$

[17] S. Janjai, P. Deeyai, (2009). Comparison of methods for generating typical meteorological year using meteorological data from a tropical environment. Applied Energy 86, 528537.

[18] Ousmane Coulibaly, Emmanuel Ouedraogo, Abdoulaye Ouedraogo et Jean Koulidiati, (2015). Détermination d'années météorologiques types utilisées pour la simulation thermique et énergétique des bâtiments de dix villes du Burkina Faso. Afrique Science 11 (6) 158-169. 